\title{
Current Perspectives in the Intersection between Emotion and Consciousness
}

\section{Stefania Righi* and Lapo Pierguidi}

Department of Neuroscience, University of Florence, Florence, Italy

\section{Editorial}

A fascinating question that went through the last decades of experimental psychology research is the relationship between emotion and consciousness. Emotions are complex pattern that require the contribution of numerous physiological, psychological and cognitive processes. In fact, they are state of feeling which give rise to physical and psychological changes that influence and actively drive our behaviors. On the one hand emotions involve the appraisal and evaluation of sensory afferent information. On the other hand they produce motivation and disposition to behave that, differently from reflexes and instincts, vary across different situations. The fact that the same central emotional state may generate very different patterns of behavior, each adaptive in a different situational context, is an important connection point with the consciousness $[1,2]$. Here, we consider the term consciousness in a broad acceptation referring to to the level of consciousness (e.g. coma, vegetative state and wakefulness), the content (that is what it is we are conscious of) as well as the self-awareness [3-6]. By this token, conscious emotional experiences may be fundamental to elaborate the cognitive and behavioral strategies which enable us to act intentionally and purposely. Hence, emotion and consciousness overlap and interact in several psychological domains and, importantly, each is necessary for some aspects of the other. For example, if we assume that some elementary characteristics of emotion, such as physiological states connected to homeostatic regulation, are important for the sense of self-continuity we establish a main role of emotion in determine conscious awareness [7-9]. Additionally, if we consider the theory of [10] emotions would be nonspecific arousal activation which became a specific emotional content only when the subjective evaluation, appraisal of situation, cognitive inferences and motivation to behave became conscious. These observations raise important issues that have been recently investigated through functional imaging [11-15] and clinical populations [16-19]. Specifically, studies have emphasize two important point which could drive further researches:

1) A large amount of evidence have suggested that both emotional states and consciousness emerge as result of neural activities which are overlapped. A wide cortical network [20] that is more activated during wakeful rest without cognitive engagement may be crucial to the maintenance of consciousness [12]. Furthermore, the cingulate cortices (anterior and posterior), the lateral parietal cortex and ventro-medial prefrontal cortex are activated when processing information associated to emotions, internal monitoring and selfawareness $[4,15,21]$. In particular, the neural activity in cingulate cortex point to a close association between consciousness and selfrepresentation, as well as to an implication in the awareness of feelings and emotions [22]. Supporting this idea bilateral lesions of the anterior cingulate cortex may cause a lack of engagement with one's environment and an absence of volitional behavior [7]. In summary, there are several cortical structures, such as the cingulate cortex, which stands out as regions that are crucial for expression, experience and motivational aspects of emotion, as well as more generally for conscious states.

2) Another important remark to address the relationship between emotion and consciousness is that both rely on the neural representations of the body arising from brain structure which process interoceptive information $[8,23]$. Interoceptive information is thought to represent the grounding for the "core self" that would be the basis for our feeling of continuity as well as for our autobiography $[7,23]$. The importance of awareness and self-perception for an adaptive emotional behavior has largely been documented [24]. Specifically, a significant body of studies on psychiatric disorders such as schizophrenia have recently suggested that disturbances of selfhood (e.g., delusions of control) may reflect problems in distinguishing self-caused from externally-caused changes in sensory input [25]. These neuroscientific evidence supports the theory of [26] that emotions arise from perceptions of changes in the body. This approach developed into 'appraisal' theories, which identify in explicit cognitions and beliefs the causes of physiological changes inducing subjective feeling states and emotional behavior [27]. Furthermore, the complex relationship between body experience and emotion was formalized by [10] in their 'two factor' theory. This theory states that emotional experience arise from the blend of physiological change and cognitive appraisal. Taking into account these theoretical perspectives a recent predictive model [28] reconsidered several neuroimaging evidence $[29,30]$ suggesting that the anterior insular cortex may occupy a central role in interconnecting emotions and consciousness. In particular, several clinical studies [3133] suggested that the anterior insular cortex may act as a comparator and generator of interoceptive inference which would connect body information with emotional experiences. In this way, awareness of self and of emotional states would emerge from a dynamic, continuous, but largely bottom-up interoceptive representational hierarchy which interacts with other sensory inputs to stimulate behavior $[9,28]$.

In the light of these evidence the interconnection between emotion and consciousness is crucial for orienting and modulating our motivated behaviors and further research is needed to clarify some still debated issues. For example, whether and to what extent an elaborated self-representation is related to a richer conscious emotional experience, or, whether there are aspects of emotional experience that are relatively independent of consciousness and thought. In particular, this last outstanding question is very interesting when considering that under certain circumstances some stimuli can trigger behavioral and emotional responses but fail to lead to conscious experience. For example, subliminally presented happy or angry faces may influence subsequent drinking behavior: thirsty participants who were shown the happy faces consumed more beverage and rated it as more pleasant then subjects who were shown neutral or angry faces [34]. Crucially, non-conscious masked faces influenced motivation without affecting participants' conscious feelings (as rated by subjects). Consistently, brain

${ }^{*}$ Corresponding author: Righi S, Department of Neuroscience, University of Florence, Florence, Italy, E-mail: stefania.righi@unifi.it

Received: December, 01, 2015; Accepted: December, 01, 2015; Published: December, 30, 2015

Citation: Righi S, Pierguidi L (2015) Current Perspectives in the Intersection between Emotion and Consciousness. Clin Depress 1: e103. doi:10.4172/cdp.1000e103

Copyright: () 2015 Righi S, et al. This is an open-access article distributed under the terms of the Creative Commons Attribution License, which permits unrestricted use, distribution, and reproduction in any medium, provided the original author and source are credited. 
Citation: Righi S, Pierguidi L (2015) Current Perspectives in the Intersection between Emotion and Consciousness. Clin Depress 1: e103. doi:10.4172/ cdp.1000e103

Page 2 of 2

imaging studies have shown substantial brain activation or emotional responses to such unconsciously processed stimuli [35]. These evidence are particularly promising to further deepen the knowledge on the interaction between emotional state and consciousness by addressing also the yet little understood topic of the dissociation between emotional state and consciousness.

\section{References}

1. Lane RD, Reiman EM, Ahern GL, Schwartz GE, Davidson RJ (1998) Neural correlates of levels of emotional awareness: evidence of an interaction between emotion and attention in the anterior cingulate cortex. Journal of Cognitive Neuroscience 10: 525-535.

2. Damasio AR, Grabowski TJ, Bechara A, Damasio H, Ponto LB, et al. (2000) Subcortical and cortical brain activity during the experience of self-generated emotions. Nature Neuroscience 3: 1049-1056.

3. Lambie JA, Marcel AJ (2002) Consciousness and the varieties of emotion experience: a theoretical framework. Psychological Review 109: 219-259.

4. Baars BJ, Banks WP, Newman JB (2003) Brain, conscious experience and the observing self. Trends in Neurosciences 26: 671-675.

5. Block N (2005) Two neural correlates of consciousness. Trends in Cognitive Science 9: 46-52.

6. Zeman A (2001) Consciousness. Brain 124: 1263-1289 Ochsner KN, Gross JJ (2005)The cognitive control of emotion. Trends in Cognitive Sciences 9: 242249.

7. Damasio A (2003) Feelings of emotion and the self. Annals of the New York Academy of Sciences 1001: 253-261.

8. Tsuchiya N, Adolphs R (2007) Emotion and consciousness. Trends in Cognitive Science 11:158-167.

9. Northoff G (2012) From emotions to consciousness - a neuro-phenomenal and neuro-relational approach. Frontiers in Psychology.

10. Schachter S, Singer JE (1962) Cognitive, social, and physiological determinants of emotional state. Psychological Review 69: 379-399.

11. Heims HC, Critchley HD, Dolan R, Mathias CJ, Cipolotti L (2004) Social and motivational functioning is not critically dependent on feedback of autonomic responses: neuropsychological evidence from patients with pure autonomic failure. Neuropsychologia 42: 1979-1988.

12. Raichle ME, Gusnard DA (2005) Intrinsic brain activity sets the stage for expression of motivated behavior. Journal of Comparative Neurology 493: 167176.

13. Liotti M, Brannan S, Egan G, Shade R, Madden L, et al. (2001) Brain responses associated with consciousness of breathlessness (air hunger). Proceedings of National. Academy of Sciences U.S.A 98: 2035-2040

14. Berthoz S, Artiges E, Van de Moortele PF, Poline JB, Rouquette S, et al. (2002) Effect of impaired recognition and expression of emotions on fronto-cingulate cortices: an fMRI study of men with alexithymia. American Journal of Psychiatry 159: 961-967.

15. D'Argembeau A, Collette F, Van der Linden M, Laureys S, Del Fiore G, et al. (2005) Self-referential reflective activity and its relationship with rest: a PET study. Neuroimage 25: 616-624.

16. Nicotra A, Critchley HD, Mathias CJ, Dolan RJ (2006) Emotional and autonomic consequences of spinal cord injury explored using functional brain imaging. Brain 129: 718-728.

17. Tranel D, Gullickson G, Koch M, Adolphs R (2006). Altered experience of emotion following bilateral amygdala damage. Cognitive Neuropsychiatry 11 : 219-232.

18. Adolphs R, Tranel D, Koenigs M, Damasio AR (2005) Preferring one taste over another without recognizing either. Nature Neuroscience 8: 860-861.

19. Owen AM, Coleman MR, Boly M, Davis MH, Laureys S, et al. (2006) Detecting awareness in the vegetative state. Science 313: 1402.

20. Craig AD (2003) Interoception: the sense of the physiological condition of the body. Current Opinion in Neurobiology 13: 500-505.

21. Fox MD, Snyder AZ, Vincent JL, Corbetta M, Van Essen DC et al. (2005) The human brain is intrinsically organized into dynamic, anticorrelated functional networks. Proceedings of National. Academy of Sciences U.S.A 102: 96739678.

22. Vogt BA (2005) Pain and emotion interactions in subregions of the cingulate gyrus. Nature Reviews Neuroscience 6: 544

23. Damasio AR (1999) The Feeling of What Happens: Body and Emotion in the Making of Consciousness, Harcourt Brace.

24. Panksepp J (2005) Affective consciousness: core emotional feelings in animals and humans. Consciousness \& Cognition 14: 30-80.

25. Frith C (2011) Explaining delusions of control: the comparator model 20 years on. Consciousness \& Cognition 21: 52-54.

26. James W (1884) What is an emotion? Mind 9: 188-205.

27. Critchley HD, Harrison NA (2013) Visceral influences on brain and behavior Neuron 77: 624-638.

28. Seth AK (2013) Interoceptive inference, emotion, and the embodied self Trends in Cognitive Sciences 17: 565-573.

29. Suzuki K, Garfinkel SN, Critchley HD, Seth AK (2013) Multisensory integration across interoceptive and exteroceptive domains modulates self-experience in the rubber-hand illusion. Neuropsychologia 51: 2909-2917.

30. Aspell JE, Heydrich L, Marillier G, Lavanchy T, Herbelin B, et al. (2013) Turning body and self inside out: visualized heartbeats alter bodily self-consciousness and tactile perception. Psychological Sciences 24: 2445-2456.

31. Synofzik M, Their P, Leube DT, Schlotterbeck P, Lindner A (2010) Misattributions of agency in schizophrenia are based on imprecise predictions about the sensory consequences of one's actions. Brain 133: 262-271.

32. Silani G, Bird G, Brindley R, Singer T, Frith C, et al. (2008) Levels of emotional awareness and autism: an fMRI study. Social Neuroscience 3: 97-112.

33. Seeley WW (2010) Anterior insula degeneration in frontotemporal dementia. Brain Structure \& Function 214: 465-475.

34. Winkielman P, Berridge KC (2004) Unconscious emotions. Current Directions in. Psychological Science 13: 120-123.

35. Jiang $Y$, He S (2006) Cortical responses to invisible faces: dissociating subsystems for facial-information processing. Current Biology 16: 2023-2029. 